\title{
Alat Pengukur Suhu Badan Dan Detak Jantung Portable
}

Pandu Igeng Jatmiko ${ }^{1}$, Arif Johar Taufiq ${ }^{2}$, Wakhyu Dwiono ${ }^{3}$

Program Studi S1 Teknik Elektro, Universitas Muhammadiyah Purwokerto

Fakultas Teknik dan Sains, Universitas Muhammadiyah Purwokerto

\section{Informasi Makalah}

Dikirim, 8 Mei 2019

Direvisi, 1Juli 2019

Diterima,

\section{Kata Kunci:}

AT-Mega328

Detak Jantung

Suhu Badan

\begin{abstract}
INTISARI
Menjaga kesehatan merupakan hal yang sangat penting bagi kehidupan. Kesehatan tubuh perlu diperhatikan bagi semua orang, terutama adalah kesehatan jantung. Jantung merupakan salah satu organ penting yang dimiliki oleh manusia yang berfungsi memompa darah ke seluruh. Detak jantung beats per menit (bpm) ini merupakan parameter untuk menunjukkan kondisi jantung. Selain jantung, yang harus diperhatikan adalah suhu badan. Perubahan suhu badan sangat erat kaitannya dengan produksi panas yang berlebihan, untuk mengetahui suhu badan diperlukan alat unutuk mengukurnya. Dalam kehidupan sehari-hari untuk mengukur suhu badan dan detak jantung harus menggunakan 2 alat ukur sehingga cukup menyulitkan, maka perlu adanya suatu alat yang dapat mengukur suhu badan dan detak jantung secara bersamaan. Alat ukur suhu badan dan detak jantung dirancang berbasis mikrokontroler AT-Mega328 menggunakan sensor DS18B20 sebagai pengukur suhu dan pulse sensor untuk mendeteksi detak jantung. Data detak jantung dan suhu tubuh ditampilkan pada LCD 16x2 dan data pengukuran disimpan pada memori mikro SD. Penelitian ini bertujuan untuk memudahkan dalam mengetahui suhu badan dan frekuensi detak jantung per menit. Selisih rata-rata antara DS18B20 dengan termometer digital adalah sebesar $0,71 \%$. Pengukuran detak jantung menggunakan pulse sensor dan beat per minute tensimeter selisihnya sebesar $2,64 \%$.
\end{abstract}

\begin{abstract}
Health is one of our biggest assets that should be maintained, it is why everyone must be concerned about it, especially heart. Heart as one of the most important human organ serves for blood pumping. Measurement of heart rate is beats per minute (bpm), this parameter shows heart conditions. Another heart, body temperature must be concerned as well. The changing of body temperature is related to the production of excessive heat, there is also a device to measure the body temperature. Usually, two devices are required to measure body temperature and heart rate, it will be easier if it is used one device to do those task at the same time. Body temperature and heart rate monitor is designed based on AT-Mega328 microcontroller using DS18B20 sensor as thermometer and pulse sensor to detect heartbeat. The body temperature and heart rate are displayed on LCD $16 \times 2$, the data are stored on Micro SD. From the test result it can be seen that the error is $0.71 \%$ for temperature measurement, and $2.64 \%$ for heart beat measurement if they are compared to standar device.
\end{abstract}

Korespondensi Penulis:

Pandu Igeng Jatmiko

Program Studi S1 Teknik Elektro

Universitas Muhammadiyah Purwokerto

Jl. Raya Dukuh Waluh Purwokerto, 53182

Email: pandujatmiko13@gmail.com 


\section{PENDAHULUAN}

Teknologi sekarang ini telah berkembang sedemikian pesatnya diberbagai bidang dalam kehidupan manusia. Teknologi yang sangat berkaitan erat dengan dunia elektronika pun merambah diberbagai bidang, salah satunya bidang kesehatan. Berbagai alat kesehatan sekarang banyak yang telah beralih dari sistem analog ke digital. Keuntungan yang bisa diperoleh dari perubahan teknologi analog ke sistem digital, mulai dari segi penghematan waktu, efisiensi alat dan komponen, hingga keakuratan suatu pengukuran. Sebagai contoh pada pengukuran suhu badan dan detak jantung biasanya dilakukan oleh dokter atau ahli kesehatan dengan berbagai cara.

Pengukuran bisa dilakukan secara manual yaitu dengan termometer dan memegang urat nadi pada pergelangan tangan. Hal ini memiliki kekurangan dalam hal keakuratan pengukuran, karena memerlukan konsentrasi penuh pada saat melakukan pengukuran suhu badan dan detak jantung. Alat yang dibuat mememiliki kelebihan dari pada menggunakan cara manual, tetapi alat yang dibuat ini juga memiliki kekurangan dari segi kepraktisan alat.

\section{METODE PENELITIAN}

Penelitian ini dilakukan dengan cara studi pustaka dan membuat alat pengukur suhu badan dan detak jantung. Perancangan alat ukur ini menggunakan masukan suhu badan, dan detak jantung yang diperoleh dari perubahan volume darah pada ujung jari. Tahapan yang dilakukan dalam perancangan sistem ini adalah melakukan perancangan perangkat lunak yaitu membuat program untuk membaca data sensor dan mengolah data sensor menjadi parameter derajat celcius dan beat per minute yang ditampilkan pada LCD dan disimpan pada memori. Tahapan selanjutnya adalah perancangan perangkat keras yang terdiri dari sensor suhu, sensor detak jantung, mikrokontroler AT-Mega 328, LCD 16x2, dan modul SD card sehingga menjadi suatu rangkaian yang saling terhubung. Kemudian setelah perangkat keras dirangkai dilakukan upload program yang telah dibuat ke dalam mikrokontroler AT-Mega 328.

\subsection{Diagram Alur Sistem}

Pada sistem alat pengukur suhu badan dan detak jantung portable terdapat tiga bagian yaitu bagian input, kontrol, dan output. Bagian input terdiri dari sensor suhu dan sensor detak jantung, bagian kontrol adalah mikrokontroler AT-Mega 328, dan bagian output terdiri dari LCD 16x2 dan modul micro SD card. Gambar 2.1 merupakan diagram alur sistem.

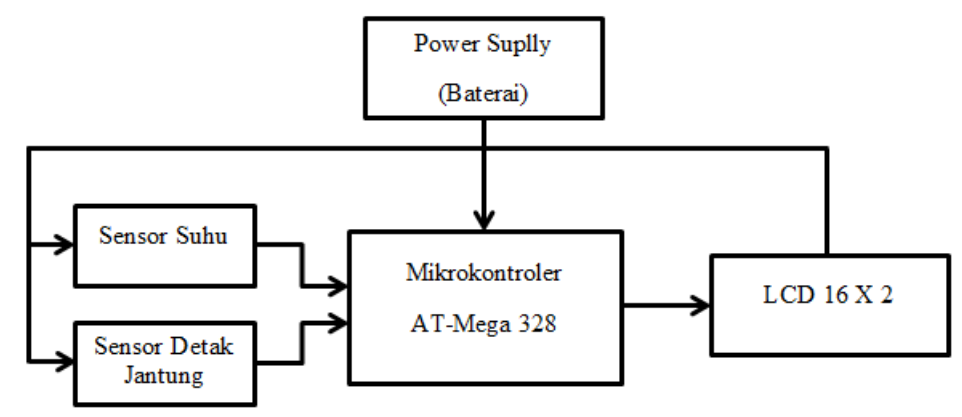

Gambar 2.1 Diagram Alur Sistem

Sensor suhu berfungsi untuk mengubah besaran panas menjadi besaran listrik sehingga dapat diproses pada mikrokontroler. Sensor detak jantung berfungsi untuk mendeteksi perubahan volume darah pada arteri jari ketika jantung memompa darah dan mengubahnya menjada sinyal supaya dapat diproses pada mikrokontroler. Pada blok kontrol terdapat mikrokontroler AT-Mega 328 yang berfungsi untuk memproses semua sinyal masukan dari sensor sehingga menghasilkan besaran suhu dalam derajat celcius dan jumlah detak jantung per menit (BPM). Pada blok output terdapat LCD 16x2 yang dapat menampilkan 32 karakter dalam 2 baris sehingga berfungsi sebagai layar yang menampilkan nilai dari suhu badan dan detak jantung permenit (BPM).

Halaman Web JRRE : http://jurnalnasional.ump.ac.id/index.php/JRRE 


\section{HASIL DAN PEMBAHASAN}

3.1 Pengujian Sensor Detak Jantung

Pengujian sensor detak jantung atau pulse sensor bertujuan untuk melihat sinyal dan tegangan keluaran dari sensor. Gambar 3.1 dan 3.2 adalah sinyal keluaran sensor detak jantung.

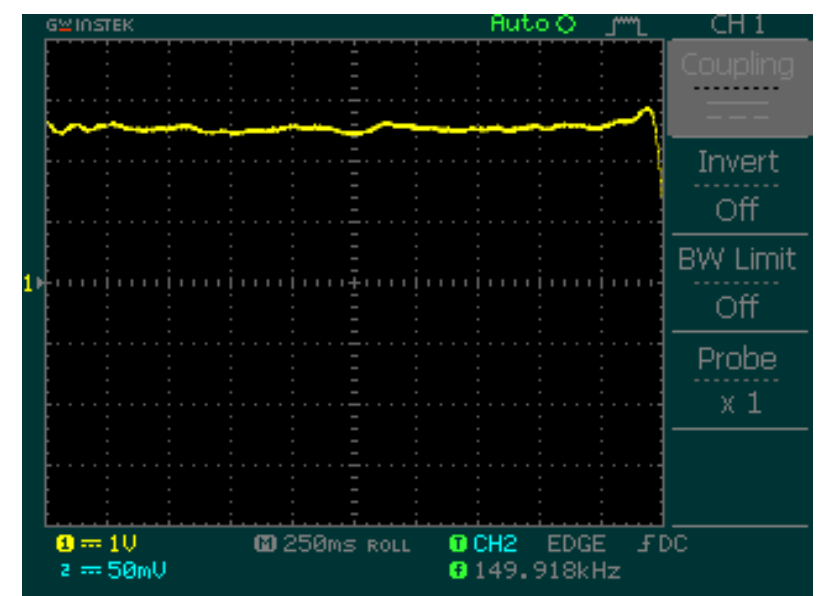

Gambar 3.1 Sinyal Keluaran Sensor Tidak Ditempelkan ke Jari

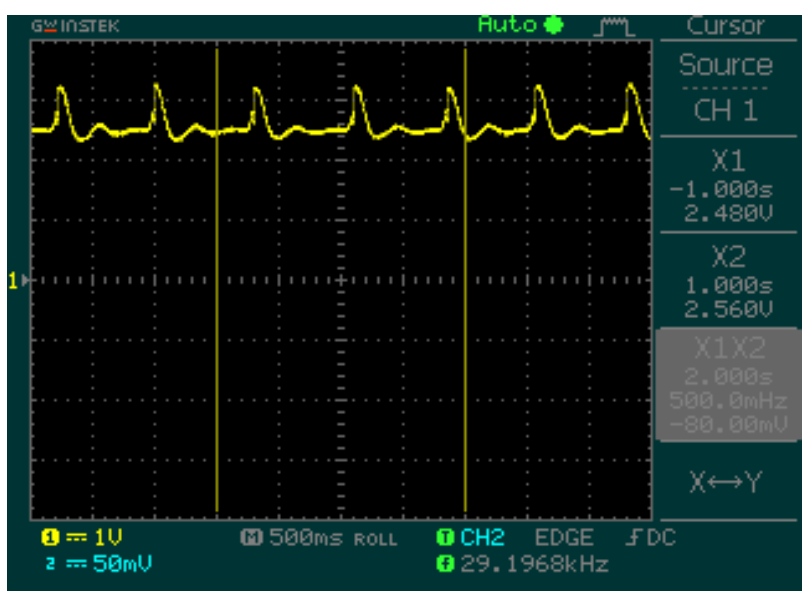

Gambar 3.2 Sinyal Keluaran Sensor Ditempelkan ke Jari

Pada Gambar 3.1 sensor detak jantung tidak ditempelkan ke ujung jari dan tidak ada media yang menghalangi pancaran cahaya LED sehingga sinyal keluaran dari sensor hanya berupa noise. Pada Gambar 3.2 sensor detak jantung ditempelkan ke ujung jari sehingga bentuk sinyal berfluktuasi sesuai dengan detak jantung yang diukur.

\subsection{Pengujian Sensor Suhu DS18B20}

Pengujian sensor suhu DS18B20 bertujuan untuk melihat sinyal dan membaca data keluaran dari sensor. Gambar 3.3 merupakan sinyal keluaran dari sensor suhu DS18B20 yang berisi data suhu dalam bentuk hexadecimal dengan menggunakan bantuan logic analyzer. 


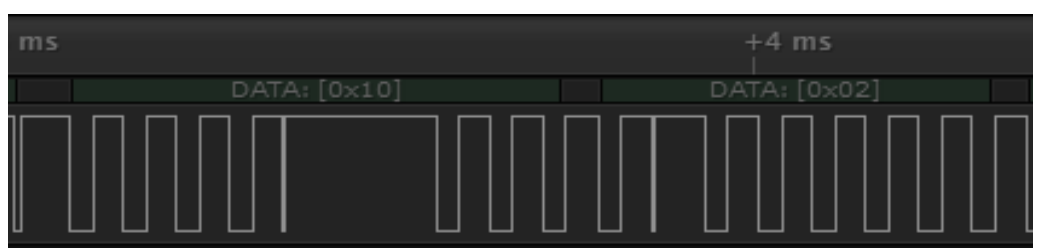

Gambar 3.3 Sinyal Digital Keluaran Sensor Suhu DS18B20

Pada gambar 3.3 data suhu yang dikirimkan dalam bentuk hexadesimal yaitu 0x10 dan 0x02 untuk merubah menjadi suhu maka ada beberapa langkah, yaitu :

1. Data 0x02 (MSB) dan 0x10 (LSB) dijadikan satu menjadi 0210 dan diambil 3 digit yaitu 210.

2. Kemudian data hexadesimal 210 dirubah menjadi desimal yaitu 528

3. Mengalikan data desimal 528 dengan 0,0625 karena menurut data sheet $1^{0} \mathrm{C}=0,0625$ maka $528 \mathrm{x}$ $0,0625=33^{0} \mathrm{C}$

\subsection{Pengujian Modul Micro SD Card}

Pengujian modul micro SD card bertujuan untuk membandingkan data yang tersimpan pada memori dengan data yang ditampilkan pada LCD 16x2. Data pada memori harus sama dengan data yang ditampilkan pada LCD 16x2 karena data yang tersimpan pada memori merupakan data yang ada pada LCD 16x2 setelah tombol simpan ditekan. Tabel 3.1 merupakan tabel pengujian modul micro SD card.

Tabel 3.1 Pengujian Modul Micro SD Card

\begin{tabular}{ccccc}
\hline \multirow{2}{*}{ Pengujian ke } & \multicolumn{2}{c}{ Data pada LCD } & \multicolumn{2}{c}{ Data Pada memori } \\
& Suhu & BPM & Suhu & BPM \\
\hline $\mathbf{1}$ & 35,75 & 75 & 35,75 & 75 \\
\hline $\mathbf{2}$ & 36,0 & 74 & 36,0 & 74 \\
\hline $\mathbf{3}$ & 36,25 & 79 & 36,25 & 79 \\
\hline $\mathbf{4}$ & 36,50 & 75 & 36,50 & 75 \\
\hline $\mathbf{5}$ & 36,69 & 75 & 36,69 & 75 \\
\hline
\end{tabular}

Menurut tabel 3.1 data suhu dan detak jantung (BPM) yang ditampilkan oleh LCD 16x2 sama dengan data yang tersimpan pada memori SD card. Tipe data yang tersimpan pada micro SD yaitu text.

\subsection{Pengujian Lama Penggunaan Baterai Terhadap Sistem}

Lama penggunaan baterai dihitung dengan membandingkan arus yang diserap setiap saat dengan kapasitas baterai. Baterai yang digunakan adalah baterai primer dengan jenis zinc carbon, tegangan yang tertera pada baterai adalah 9 Volt dan kapasitas arus 400 mAh. Sedangkan sistem membutuhkan tegangan 5 Volt dan arus $95 \mathrm{~mA}$. Lama penggunaan baterai dihitung dengan membagi kapasitas arus pada baterai dan arus yang digunakan pada sistem, perhitungannya sebagai berikut :

$$
\begin{gathered}
\text { Lama peng gunanaan }=\frac{\text { kapasitas baterai }(\mathrm{mAh})}{\text { Arus beban }} \\
=\frac{400 \mathrm{mAh}}{95 \mathrm{~mA}}=4,21 \mathrm{~h}
\end{gathered}
$$

Dari perhitungan lama penggunaan baterai dapat disimpulkan bahwa sistem dapat bekerja selama 4,21 jam. 


\subsection{Pengujian Alat Pengukur Suhu Badan dan Detak Jantung Protable}

Tabel 3.2 Pengujian Alat Pengukur Suhu Badan dan Detak Jantung Portable

\begin{tabular}{|c|c|c|c|c|c|c|c|c|c|}
\hline \multirow{2}{*}{ No } & \multirow{2}{*}{ Nama } & \multirow{2}{*}{$\begin{array}{c}\text { Jenis } \\
\text { Kelamin }\end{array}$} & \multirow{2}{*}{ Usia } & \multicolumn{2}{|c|}{ Suhu Badan } & \multirow{2}{*}{$\frac{\text { Error }}{(\%)}$} & \multicolumn{2}{|c|}{ Detak Jantung } & \multirow{2}{*}{$\frac{\text { Error }}{(\%)}$} \\
\hline & & & & Alat & Termometer & & Alat & BPM & \\
\hline 1 & Syaefudin & Laki-laki & 23 & 36,1 & 36,5 & 1 & 83 & 80 & 3,75 \\
\hline 2 & Pandu Igeng & Laki-laki & 24 & 36,2 & 36,4 & 0,54 & 75 & 72 & 4,16 \\
\hline 3 & Imam G & Laki-laki & 24 & 36,1 & 36,3 & 0,55 & 72 & 74 & 2,7 \\
\hline 4 & Badrul U & Laki-laki & 22 & 34,8 & 35,2 & 0,56 & 78 & 75 & 4 \\
\hline 5 & Irawan A & Laki-laki & 20 & 35,5 & 36 & 1,38 & 64 & 66 & 3,03 \\
\hline 6 & Setyo A & Laki-laki & 21 & 35,7 & 36 & 0,83 & 75 & 76 & 1,31 \\
\hline 7 & Bayu A & Laki-laki & 22 & 35,8 & 36,3 & 1,37 & 63 & 65 & 3,07 \\
\hline 8 & Bowo M & Laki-laki & 26 & 35,8 & 36,2 & 1,65 & 77 & 80 & 3,75 \\
\hline 9 & Dika N & Laki-laki & 22 & 35,7 & 36 & 0,83 & 66 & 70 & 5,71 \\
\hline 10 & Lutfatul L & Perempuan & 24 & 36 & 36,2 & 0,55 & 69 & 71 & 2,81 \\
\hline 11 & Sadariyah T & Perempuan & 22 & 36,5 & 36,8 & 0,81 & 95 & 98 & 3,06 \\
\hline 12 & Eka P.W & Perempuan & 22 & 36 & 36,2 & 0,55 & 89 & 92 & 3,26 \\
\hline 13 & Iqbal Fauzi & Laki-laki & 24 & 36,4 & 36,5 & 0,27 & 84 & 83 & 1,2 \\
\hline 14 & Oryza L & Laki-laki & 24 & 36 & 36,3 & 0,82 & 80 & 81 & 1,23 \\
\hline 15 & Anggi R & Laki-laki & 21 & 36,5 & 35,7 & 0,56 & 83 & 82 & 1,21 \\
\hline 16 & Aida I & Perempuan & 19 & 37,4 & 37,6 & 0,53 & 106 & 104 & 1,92 \\
\hline 17 & Rachmi G & Perempuan & 22 & 36,5 & 36,6 & 0,27 & 100 & 97 & 3,09 \\
\hline 18 & Latif Efendi & Laki-laki & 19 & 36,5 & 36,8 & 0,81 & 92 & 89 & 3,37 \\
\hline 19 & Rizky J & Laki-laki & 23 & 36,6 & 36,7 & 0,27 & 105 & 108 & 2,77 \\
\hline 20 & Tangguh W & Laki-laki & 22 & 36.7 & 36,8 & 0,27 & 99 & 101 & 1,98 \\
\hline 21 & Taufik H & Laki-laki & 22 & 35,8 & 36,2 & 1,1 & 84 & 82 & 2,43 \\
\hline 22 & Fajar Dimas S & Laki-laki & 19 & 34 & 34,3 & 0,87 & 80 & 77 & 3,89 \\
\hline 23 & Muflih A.F & Laki-laki & 23 & 36,6 & 36,4 & 0,54 & 98 & 101 & 2,97 \\
\hline 24 & Linda $P$ & Perempuan & 30 & 37,3 & 37,5 & 0,53 & 85 & 87 & 2,29 \\
\hline 25 & Bambang S & Laki-laki & 32 & 36,6 & 36,8 & 0,54 & 62 & 66 & 6,06 \\
\hline 26 & Ngadirah & Perempuan & 38 & 36,7 & 37 & 0,81 & 78 & 80 & 2,5 \\
\hline \multirow[t]{3}{*}{27} & Bayu F & Laki-laki & 17 & 35,8 & 36 & 0,55 & 61 & 59 & 3,38 \\
\hline & \multicolumn{5}{|c|}{ Jumlah } & 21,52 & & & 79,29 \\
\hline & \multicolumn{5}{|c|}{ Rata-rata error (\%) } & 0,71 & & & 2,64 \\
\hline
\end{tabular}


Pada Tabel 3.2 didapatkan rata-rata presentase kesalahan 0,71 untuk pengukuran suhu badan dan 2,64 untuk pengukuran detak jantung per menit. Hasil presentase kesalahan pengukuran tersebut didapat dari beberapa hal antara lain saat pengukuran keadaan tubuh tidak tenang dan rileks, performa komponen yang digunakan sudah menurun, kondisi tegangan baterai sudah menurun.

\subsection{Pengujian Lama Penggunaan Baterai Terhadap Sistem}

Lama penggunaan baterai dihitung dengan membandingkan arus yang diserap setiap saat dengan kapasitas baterai. Baterai yang digunakan adalah baterai primer dengan jenis zinc carbon, tegangan yang tertera pada baterai adalah 9 Volt dan kapasitas arus $400 \mathrm{mAh}$. Sedangkan sistem membutuhkan tegangan 5 Volt dan arus $95 \mathrm{~mA}$. Lama penggunaan baterai dihitung dengan membagi kapasitas arus pada baterai dan arus yang digunakan pada sistem, perhitungannya sebagai berikut :

$$
\begin{array}{r}
\text { Lama peng gunanaan }=\frac{\text { kapasitas baterai }(\mathrm{mAh})}{\text { Arus beban }} \\
=\frac{400 \mathrm{mAh}}{95 \mathrm{~mA}}=4,21 \mathrm{~h}
\end{array}
$$

Dari perhitungan lama penggunaan baterai dapat disimpulkan bahwa sistem dapat bekerja selama 4,21 jam.

\section{KESIMPULAN}

Dari hasil penelitian alat pengukur suhu badan dan detak jantung portable diperoleh hasil mulai dari tahap perancangan hingga pengujian alat sehingga dapat ditarik kesimpulan serta diajukan saran-saran untuk penelitan selanjutnya. Kesimpulan dan saran dalam Tugas Akhir ini sebagai berikut:

1. Pengukuran suhu badan dan detak jantung dapat menggunakan sensor suhu DS18B20 sebagai pengukur suhu badan dan pulse sensor sebagai pengukur detak jantung per menit (BPM).

2. Penyimpanan data hasil pengukuran ke memori mikro SD dapat menggunakan modul micro SD card, kemudian data hasil pengukuran dapat dicetak.

3. Metode pengukuran suhu badan pada sistem ini dengan mengubah besaran panas menjadi data digital dengan memanfaatkan sensor DS18B20, dan pengukuran detak jantung dengan memanfaatkan pulse sensor unutk mendeteksi perubahan volume darah pada ujung jari akibat jantung yang memompa darah.

4. Pada pengujian alat pengukur suhu badan dan detak jantung portable di dapatkan rata-rata error sebesar $0,71 \%$ untuk suhu badan dan 2,64\% untuk detak jantung per menit (BPM).

\section{DAFTAR PUSTAKA}

[1] Ananda Purwanto, Prasetyo. 2014. Rancang Bangun Alat Pengukur Tinggi Badan dan Suhu Badan Digital Berbasis Raspberry Pi. Purwokerto : Universitas Muhammadiyah Purwokerto.

[2] Andrianto, Heri.\& Darmawan, Aan. 2015. Arduino Belajar Cepat dan Pemrograman. Bandung : Informatika

[3] Indah, Sari. 2012. Suhu Tubuh (Online) (http://sariindah891.blogspot.co.id/2012/12/suhu-tubuh.html diakses tanggal 13 September 2017 pukul 21.35)

[4] Kusuma,Wahyu \& Sendy Frandika. 2014. Alat Pengukur Jumlah Detak Jantung Berdasarkan Aliran Darah Ujung Jari. Depok : Universitas Gunadharma. Vol.8 Oktober 2014, ISSN 2302-3740.

[5] Riyanto, Eddy. 2016. Perancangan Pengukur Detak Jantung dan Suhu Tubuh Berbasis Arduino Serta Smartphone Android. Surakarta : Universitas Muhammadiyah Surakarta. 